\title{
A PARADIGM SHIFT IN THE MANAGEMENT OF MUSTH AMONG BULL ELEPHANTS IN CAPTIVITY IN SRI LANKA
}

\author{
Charles Santiapillai $^{{ }^{*}}$, Bruce Read ${ }^{2}$, Gary Jacobson ${ }^{2}$, S. Wijeyamohan ${ }^{3}$ and Sunel Rambukpotha ${ }^{4}$ \\ ${ }^{1}$ Formerly of the Department of Zoology, University of Peradeniya, Peradeniya, Sri Lanka \\ ${ }^{2}$ Ringling Bros. and Barnum \& Bailey Center for Elephant Conservation, 12850, Old Grade Road, Polk \\ City, Florida, USA \\ ${ }^{3}$ Postgraduate Institute of Science, University of Peradeniya, Peradeniya, Sri Lanka \\ ${ }^{4}$ The Temple of the Tooth, Kandy, Sri Lanka \\ Accepted 20 May 2011
}

"And those who were seen dancing were thought to be insane by those who could not hear the music"

Friedrich Nietzsche

\begin{abstract}
The phenomenon of musth among Asian elephants has been known since ancient times. Musth is a temporary post-pubertal, reproductive phenomenon commonly observed in the healthy male Asian elephant (Elephas maximus) both in the wild and in captivity. However, the treatment of musth bulls in Asia has remained almost unchanged. The traditional way of dealing with musth bulls involves restraining the animals by tethering them to trees and reducing the food intake so as to weaken them, with the assumption that they would drop out of musth faster. But such methods can cause severe wounds on the legs from the ropes used to tie the animals, and make the bulls more aggressive and traumatic, thereby posing a serious danger to their keepers or mahouts. The alternative method described in the paper provides a strong, safe, and secure tool for the management of musth bulls in captivity. The method not only assures the safety of the bulls but ensures that of the mahouts as well. Being a predominantly Buddhist country, Sri Lanka can lead the way in promoting the bull pen as an alternative tool in the management of bulls in musth, while assuring the utmost safety of their keepers.
\end{abstract}

Key words: musth, Asian elephant, mahouts, bull pen, Elephas maximus

\section{INTRODUCTION}

The phenomenon of musth in Asian elephants was known since ancient times, long before it was recognized among African elephants. It has been described accurately in the Indian literature (Edgerton, 1931; LahiriChoudhury, 1992). The Rig-Veda (1500-1000 B.C) alludes to a musth bull when describing the strength of Indra, the King of Gods. The most popular and influential book of Buddhist canonical literature, The Dhammapada (in Radhakrishnan, 1950) compiled probably in the third century before Christ, refers explicitly to the phenomenon of musth as follows: "The elephant called Dhanapalaka is hard to control when the temples are running with a pungent sap. He does not eat a morsel (of food) when bound."

Musth is a temporary post-pubertal, reproductive phenomenon commonly observed in the healthy male Asian elephant (Elephas maximus) both in the wild and in captivity, brought on by increased levels of androgen. It is characterized by increased aggressive behaviour and copious discharge of a thick, pungent smelling tar-like oily fluid from the temporal glands, which stains much of the lower part of the face. Musth bulls also do not urinate, instead they dribble (Pooke, 1996). Sanderson (1878) and Williams (1989) regard musth as a form of "sexual madness". Deraniyagala (1955) attributes the derivation of the word musth probably to the Sinhala word madha, while others trace it to an Urdu word mast meaning "intoxicated" (Poole, 1987; Sukumar, 2003) or "crazy-in-the-head" (Kahl and Armstrong, 2002). While socially immature bulls emit sweet smelling honey-like odours such as esters and alcohols to reduce conflict with adult bulls, older males broadcast malodorous combinations such as frontalins and nonanone to deter young males (Rasmussen et al., 2002).

In Sri Lanka, there is still some uncertainty over the occurrence and frequency of musth. It appears that when young bulls between the ages

\footnotetext{
*Corresponding author's email: charlessantiapillai@gmail.com
} 
of 15-20 years first come into musth, they are a bit confused; they become disobedient, irritable and are prone to attack people or even their mahouts.

Some elephant handlers or mahouts in Sri Lanka believe that musth is not a seasonal phenomenon but may occur any time of the year. However, the Dutchman, Cornelius Taay van Wezal who in 1713 visited the island observed that elephants came into musth in January and February and seldom outside these months (de Vos, 1898). However, one of the authors of this paper, namely Mr. Sunel Rambukpotha with 40 years of experience in managing elephants in captivity has recorded that musth period could last from February to May. According to Jainudeen et al., (1972) there could be two peaks of musth, one from January to April and another from August to November, coinciding with the two periods of maximum rainfall. Musth among captive bull elephants may last from two weeks to about five months and affects every adult bull once annually unless the animal is in poor body condition (Deraniyagala, 1955; Jainudeen et al., 1972). Secretions of the temporal gland may be correlated with reproductive activity (Perry, 1953), but it is not a precondition since nonmusth bulls are known to breed successfully in captivity (Carrington, 1958). Short (1966) confirmed that the act of copulation is independent of the secretion of the temporal glands.

The first symptom of musth is usually a puffiness and dampness of the temporal glands (Ferrier, 1947). When bull elephants come into musth, their behaviour changes and they become highly dangerous to both man and other elephants. Nevertheless, there are exceptions. According to personal observations of Mr. Sunel Rambukpotha, there is incontrovertible evidence of a bull elephant in full musth belonging to the Basnayake Nilame, Mr. Anton Tennakoon taking part in the annual Karal Perahera in Ratnapura from 1996 to 2000. Contrary to all previous records, this animal showed no signs of aggression towards its mahout. In captivity, musth bulls continually challenge their environment, including their mahouts, other elephants and physical barriers (Lehnhardt and Galloway, 2008). The intensity of musth increases with age, body condition, nutrition and perhaps social status (Jainudeen et al., 1972; Cooper et al., 1990; Lincoln and Ratnasooriya, 1996).

Janinudeen et al., (1972) recognize two arbitrary stages of musth. In the first stage, the onset of musth is usually indicated by the gradual enlargement of the temporal glands and the increased irritability of the animal concerned. The animal becomes so irritable and nervous that it becomes dangerous and unresponsive to its owner or keeper (mahout) or both. In general, a bull coming into musth will dramatically reduce its intake of food and live off on its fat reserves. In the next two weeks, a slight discharge from the temporal glands becomes evident and it is during this phase that the animal is highly dangerous to its keeper or mahout. At this time, the work elephants are handled very cautiously by chaining their hind legs together to restrict their movement (Jainudeen et al., 1972). The second stage is characterized by increased aggressive behaviour and temporal gland secretions. As the animal is irritable and unmanageable, it is completely restrained. It is during this phase that the animal shows its anger towards its keeper by throwing food or palm logs. Temporal gland secretion becomes copious and the animal starts to dribble urine deep yellow in color. The urine contains soluble pheromones to advertise the animal's state. According to Jainudeen et al. (1972), once this phase of urine dribbling ends, it is possible to handle most animals irrespective of whether or not the temporal glands are secreting.

A well experienced mahout can always predict in advance the onset of musth on the basis of the early symptoms, and take proper measures to secure the animal concerned in a convenient place for management. Given the dangerous and unpredictable nature of musth, the emphasis in Sri Lanka is to restrict the movement of the animal. The usual practice is to tie the animal to a tree and reduce its food intake and water so that the animal becomes weak. Mahouts believe that a weakened animal is more likely to come out of musth faster than a well-fed one. In many instances the chains are so short that the bull has hardly any way of exercising and hence becomes even more irritable and aggressive. In the initial stage of musth, the bull's hind legs are chained together to restrict its movement, but in the second stage, the animal is restrained by chaining one hind leg and one foreleg to posts or trees (Jainudeen et al., 1972). Sometimes, when a musth bull is highly aggressive and uncontrollable, it is made immobile by chaining all its four legs to trees or posts. In such a state, the animal becomes even more intractable and irritable and will pull its legs to break the ropes and thereby sustain injuries to its legs. Mahouts usually shift the restraint from one leg to another to minimize injuries, but even so, necrosis of the skin is not uncommon. 
Musth in working elephants means loss of work and therefore it entails an economic loss to their owners as well. But in Sri Lanka, it appears that musth is not suppressed by subjecting the animals to hard work, since it can affect their health. Hence, there is a general reluctance to meddle with musth using any medicine, for fear that musth may re-occur unexpectedly. The sooner the animal gets out of musth on its own, the better it is. One way of shortening the duration of musth is through the provision of food items that are low in nutritional value. High-energy foods are avoided as they are likely to prolong the musth (Preecha et al., 2005). According to Deraniyagala (1955), one of the ways of shortening the period of musth is by frequently prodding the nerve centre on the anal fold known as the Guda Marge with the ankus a rather painful experience. In India, musth bulls are not kept on a starvation diet, instead they are at times given a dose of opium or even tobacco to keep them from making a nuisance of themselves (Bedi, 1969). One mahout referred to the practice of cleaning the opening of the temporal glands with a local plant, 'Diyamederiya' following the cessation of musth.

While some elephants in musth can be handled as usual, most become dangerously unpredictable. Nevertheless, in Sri Lanka they are still handled in free contact by their keepers or mahouts. This had led to the unfortunate death of a large number of people and mahouts (Lehnhardt and Galloway, 2008). This highlights the need for an alternative method of management for bulls coming into musth.

The alternative is to develop a tool (facility) that allows the bull to pass into musth and let the natural progression of the musth period reach its end. This tool (facility) will allow the elephant to display natural behaviours in an unrestricted environment while giving the mahout and managers full access to the animal from a safe position.

Elephants have a religious significance in Sri Lanka for the Buddhists and Hindus. As such the management of elephants has been a part of the Sri Lankan culture for many years. Trained elephants have been extensively used in war and peace. They could be an important power source in forestry operations (Santiapillai and Widodo, 1992; Kurt et al., 2008). But the use of bull elephants both in war and peace is limited as and when they come into musth during which time they are dangerous. Despite the sentiment of sacredness that elephants evoke among almost all Sri Lankans, many of them are kept chained in captivity and in social isolation. Today, it is becoming increasingly clear that we need to employ more humane methods to improve the management of elephants in captivity.

\section{MATERIALS AND METHODS}

\section{Study site}

Given this situation, Ringling Bros. and Barnum \& Bailey Center for Elephant Conservation (CEC) decided to assist the government of Sri Lanka by establishing a program with the Temple of the Tooth in promoting an alternative but a safe method for mahouts to manage musth bulls. As the first stage in the program, the CEC signed a Memorandum of Understanding on March 23, 2008 with the Custodian of the Sacred Temple of the Tooth in Kandy to build a strong, durable, extensive, state of the art holding pen for dealing with elephants in musth. The bull pen was completed at a cost of US\$ 87,000 and handed over to the Diyawadana Nilame, the Custodian of the Sacred Temple of the Tooth on March 25, 2009.

The facility (Figs. 1 and 2) has two large areas (Stalls 2 \& 3) measuring 20 x $40 \mathrm{ft}$ with bare earth as the floor. Gates A and D provide access to the musth bulls. The two large stalls are connected by gates $\mathrm{F} \& \mathrm{C}$ to two smaller feeding and watering areas measuring $7 \times 20 \mathrm{ft}$ (Stalls 1 \& 4) with concrete floors. It is only in these smaller pens (Fig. 3), the elephant is provided with food and water, and nowhere else. Thus the animal will come to realize that these are safe zones where it is assured of food and water. Opposite the feeding pens are two trunk resting bars $1 \& 2$.

\section{Study animals}

In 2009, an elephant named Kandula from the Temple of the Tooth in Kandy became the first animal to be introduced into the bull pen to test how it adjusted to its new circumstances during musth. In the absence of chains, the animal took full advantage of the space and the freedom to move about inside the bull pen. The animal was observed for 79 days during which several behavioural aspects were observed and recorded.

A second bull elephant named Wijaya Raja was introduced into the bull pen, but it failed to come into musth during the 17 days it remained inside. 


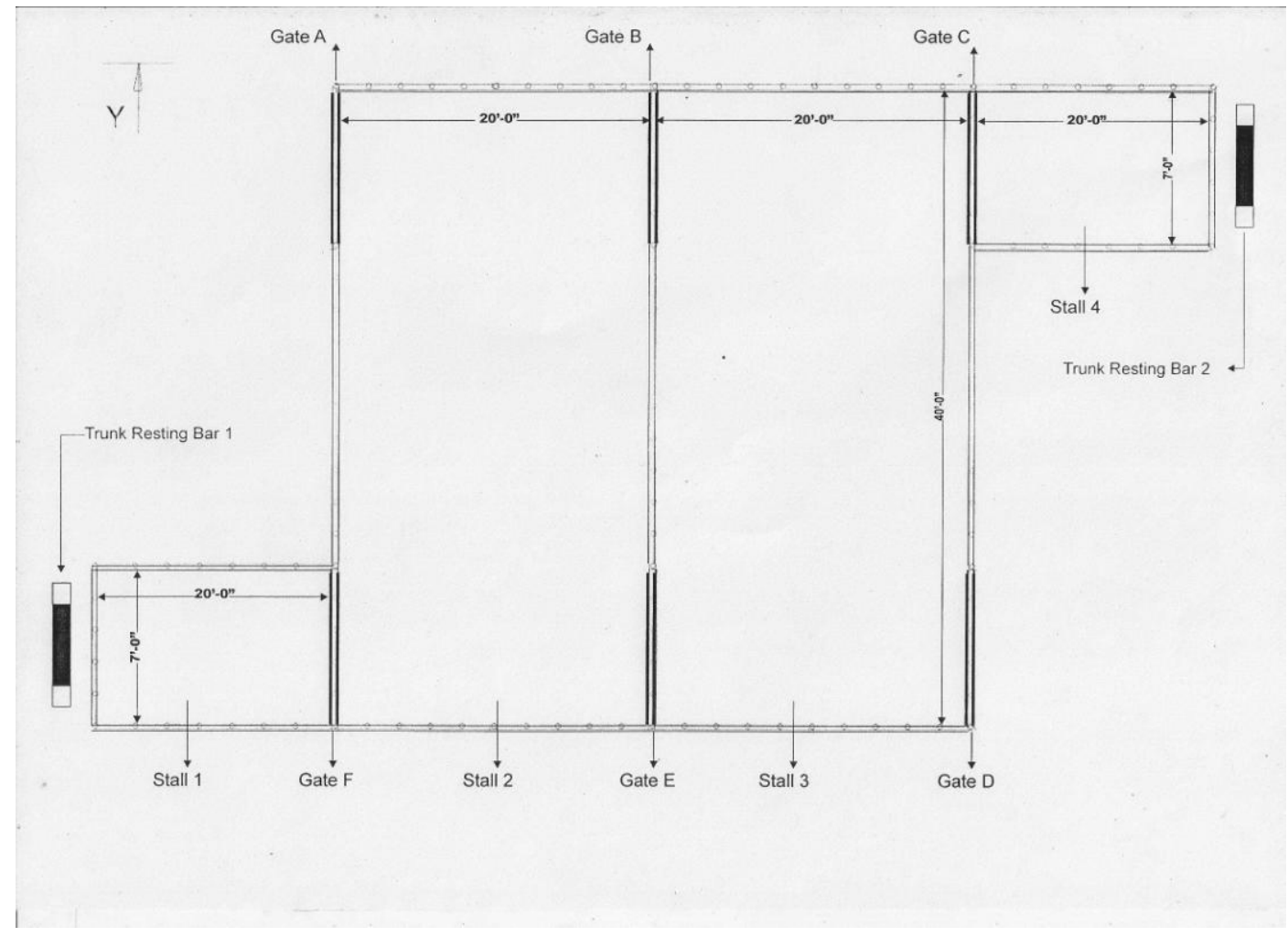

Figure 1. Ground plan of the bull pen. Stalls 1 and 4 are feeding pens, while stalls $2 \& 3$ are holding pens where elephants are kept unchained.

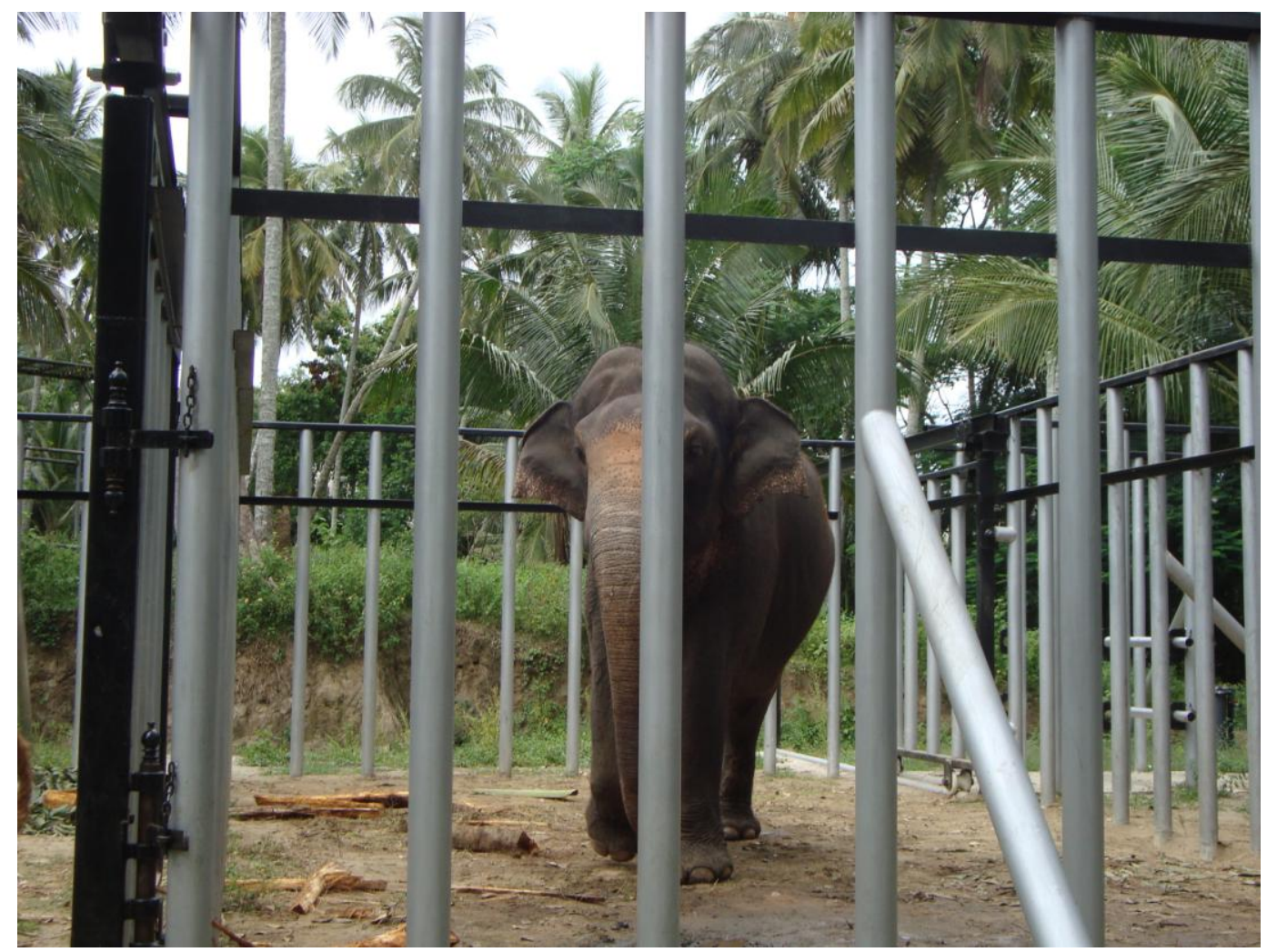

Figure 2. An adult male elephant in musth being managed inside the larger holding pen without recourse to chains or ropes. (Photo: Rukmali Athurupana) 


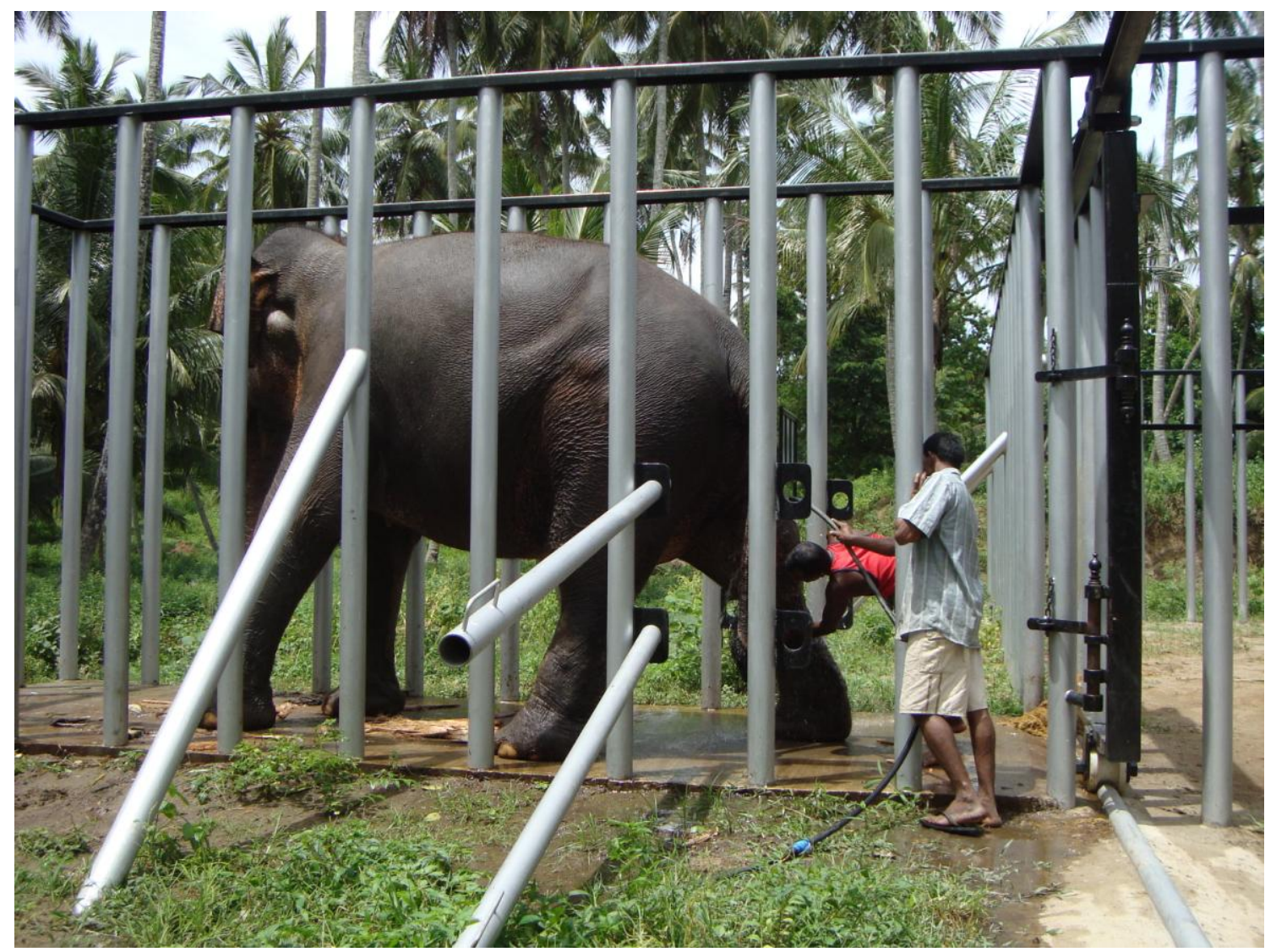

Figure 3. A bull elephant inside the smaller feeding pen being cleaned and washed by the mahout. The pen can also be used to treat wounds or administer injections by veterinarians. The butt bars can further limit the space available to the elephant. (Photo: Rukmali Athurupana)

\section{RESULTS}

The male elephant in musth introduced into the bull pen immediately began inspecting its pen and observing all the activities around it. In particular it paid more attention to the man tending cattle nearby. At first the animal was very tolerant of the herdsman and appreciated him for occasionally providing water (via a tap) for drinking, and throwing food into the feeding pen. During this time one of the cows and a she goat littered, and naturally the herdsman devoted more time with his cattle and goat than with the elephant. Since then the bull elephant took a strong dislike to the herdsman and would charge at him if he happened to be close by. Once the musth was over, the animal came out of the bull pen in good condition, without a single wound or abrasion. This experiment therefore underlines the importance of the bull pen as an alternative method of managing bull elephants in musth without a risk to both mahout and its keeper.

\section{Protocol for training bulls}

\section{(a) Placing the elephant in the bull pen}

Step 1. Position the truck carrying the elephant at either Gate A or D

Step 2. Open Gate A or D and have a person stay near the Gate concerned.

Step 3. Walk or shift the elephant through Gate A or D into Stall 2 or 3.

Step 4. Remove the chains on the elephant.

Step 5. Once the elephant is inside Stall 2 or 3, ensure the Gate $\mathrm{A}$ or $\mathrm{C}$ is closed and the mahout remains outside the holding pen. 
(b) Conditioning the elephant to enter the feeding stalls (1 \& 4)

Step 1. Check to see the Gates C \& F are closed. Step 2. Allow the elephant to investigate Stall 2 or 3 , during which keep talking to the elephant to calm him down.

Step 3. While the elephant remains inside Stall 2 or 3, do not enter the stall, or have any contact with the animal, or offer food or water.

Step 4. Make sure that food and water are provided only in Stall 1 or 4 and nowhere else.

Step 5. Place food at the far end of the Stall 1 or 4 , near the water trough.

Step 6. Remove butt bars in Stall 1 or 4 .

Step 7. Position the mahout behind the trunk resting bar.

Step 8. Have a second person open Gate C or F. This person needs to exercise caution when approaching the gate since the elephant can reach through the bars.

Step 9. Have a third person stand by Gate A or $\mathrm{D}$ and call the elephant over and let it focus its attention on him while the person in charge of Gate C or F opens it.

Step 10. Once the Gate $\mathrm{C}$ or $\mathrm{F}$ is open, the mahout must call the elephant to enter the Stall 1 or 4 (make sure he uses the same call to the elephant each time the animal is made to enter the stall).

Step 11. Give the elephant about 20 minutes to come towards the mahout and food. If it has not entered the Stall 1 or 4 during this time, close the gate and walk away from the bull pen. Do not talk or reward the elephant in any way.

Step 12. Wait for 30 minutes and repeat the introduction to Stall 1 or 4 until the elephant comes to the mahout. This may take several attempts until the elephant learns the routine. This practice session should only be repeated 4 times in one day.

Step 13. Once the elephant is conditioned to enter the Stall 1 or 4, close the Gate $\mathrm{C}$ or F and secure the Gate.

Step 14. Repeat the introduction procedure until the elephant demonstrates consistently responding to the mahout's call.

\section{(c) The use of the butt bars}

Step 1. When conditioning the elephant in Stall 1 or 4 , remove the butt bars and do not begin using them until the elephant is conditioned to standing inside.

Step 2. When the elephant is used to standing in Stall 1 or 4 , then call him to come forward and decide where to place the butt bars.
Step 3. To hold the elephant in place, first pass a rope through the top guide behind the elephant.

Step 4. Once the rope is in place, move the second butt bar through the lower guides and secure it in place.

Step 5. Remove the rope and place the top butt bar through the guides. Secure the bar.

Step 6. To allow the elephant to leave, remove the lower butt bar first, and then the top bar, and then open the gate $\mathrm{C}$ or $\mathrm{F}$.

Step 7. The mahout should give the release command and allow the elephant to back out at its own pace.

Step 8. Once the elephant is out of Stall 1 or 4, and is inside Stall 2 or 3, close the Gate C or F.

Step 9. Clean the Stall 1 or 4 and butt bars.

\section{(d) Cleaning procedure for the bull pen}

Step 1. Shift the elephant to Stall 1 or 4. Monitor the elephant by talking to him and offering reward for calm behaviour, while the animal is inside Stall 1 or 4.

Step 2. Close Gate C or F.

Step 3. Open Gate A or D.

Step 4. Enter Stall 2 or 3.

Step 5. Remove all manure, leaves, clutter, fill holes, and level the ground.

Step 6. Inspect the stall for any defects in need of repair. If there is something that needs attention, inform the manager of the facility.

Step 7. Remove all tools and equipment from Stall 2 or 3.

Step 8. Close and secure the Gate A or D.

Step 9. Open Gate C or F

Step 10. Allow the elephant to back out of Stall 1 or 4.

Step 11. Once the elephant has left the stall, close and secure Gate $\mathrm{C}$ or F.

Step 12. While the elephant is in Stall 2 or 3, enter Stall 1 or 4 and remove all manure, food, clutter. Then hose down and disinfect the floor of the stall. Inspect the stall for anything that needs repair or maintenance. If there is something that needs attention, notify the manager of the facility.

\section{(e) Conditioning the elephant to place its trunk on the trunk resting bar and holding it there}

Step 1. The mahout asks the elephant to touch (or rest its trunk on the bar) resting bar with it $\mathrm{s}$ trunk. When the elephant touches the bar with its trunk reward the elephant. Then give the release command.

Step 2. Repeat this routine until the elephant touches the bar on command. 
Step 3. Give the command to the elephant to touch the bar. Once the elephant touches the bar the mahout places his hand on the trunk and commands the elephant to keep touching the bar. While the elephant is touching the bar and the mahout is holding the trunk give the elephant verbal praise. The mahout should hold the trunk for a short time and then release the trunk and give the command for the elephant to stop touching the bar.

Step 4. Once the elephant removes its trunk from the bar its gets rewarded.

Step 5. Repeat this routine. Keep the training period short and always end with the elephant completing the task.

Step 6. Once the elephant responds to the command on a regular basis, givefood rewards only occasionally, but always give verbal rewards.

\section{DISCUSSION}

The traditional method of dealing with musth bulls in Sri Lanka relies on tethering them to trees and reducing their food intake. The alternative method that we recommend here provides an opportunity for the elephant to come out of musth in the absence of chains and other forms of torture. The bull elephant is brought out of musth through positive reinforcement. The large enclosure and the routine training imparted to the animal ensure that it recovers from musth with little harm to itself and complete protection to its keeper. As far back as 2000 years ago, the Arthashastra of Kautiliya recommended the establishment of a fenced area for tamed elephants. The bull pen described here aims to assure the bull elephant a sense of security and safety given that the animal is able to retain some control over its environment, rather than being tied on all fours to trees twenty four hours a day, for up to three months. The emphasis of good management is in the provision of opportunities that allow the elephant to express a full complement of behavioural responses similar to those in nature (Markowitz, 1978). Restricting its movement is not the right way of achieving it.

The facility will certainly ensure the safety of both the mahout and his elephant since the two would be separated spatially at all times until the musth is over. Thus it would mean that adult bull elephants will not be kept in situations where direct human contact is the only means of control. Besides, there is little need to use the ankus, chains or ropes to restrain the animal since management is done through conditioning the animal to follow a routine prior to the onset of musth and making sure that it is adhered to during the musth period as well.

The bull pen donated to the Sacred Temple of the Tooth in Kandy by Ringling Bros. Barnum and Bailey's Center for Elephant Conservation offers an alternative management tool that would ensure the safety of both bull elephants and their mahouts. The importance of the bull pen lies in the fact that no such facility exists anywhere in Asia. Sri Lankan experience may help change the management of musth bulls in other countries as well. The bull pen (Fig. 2) has the potential to reduce injuries to the elephants and ensure the safety of both elephants and mahouts. Being a predominantly Buddhist country, Sri Lanka can lead the way in promoting the bull pen as an alternative tool in the management of bulls in musth, while assuring the utmost safety of their keepers.

\section{ACKNOWLEDGEMENTS}

We express our thanks to The Feld Entertainment, Inc. based in Virginia, USA for constructing the bull pen, and thereby providing us an opportunity to demonstrate its usefulness in managing musth bulls without ropes and chains. We would like to acknowledge the support given by the Diyawadana Nilame of the Sacred Temple of the Tooth, Kandy in using the bull pen.

\section{REFERENCES}

Alagoda, D. (2006). A preliminary study of the management of elephants in captivity in Sri Lanka.Unpublished report for the Ringling Bros. and Barnum \& Bailey Center for Elephant Conservation (CEC) based in Polk City, Florida, USA.

Bedi, M. (1969). Elephant: Lord of the Jungle. National Book Trust, India.

Carrington, R. (1958). Elephants: a short account of their natural history, evolution, and influence on mankind. Chatto and Windus, London.

Cooper, K.A., Harder, J.D., Clawson, D.H., Fredrick, D.L., Lodge, G.A., Peachey, H.C., Spellmire, T.J. and Winstel, D.P. (1990). Serum testosterone and musth in captive male African and Asian elephants. Zoo Biology, 9: 297-306. 
Deraniyagala, P.E.P. (1955). Some extinct elephants, their relatives and the two living species. Ceylon National Museum Publication, Colombo.

de Vos, F.H. (1998). A pertinent account and detailed description of the character, nature, coitus, and production of Elephants in the island of Ceylon" Translated by F.H. de Vos in the Journal of the Ceylon Branch of the Royal Asiatic Society, XV: 176-200.

Edgerton, F. (1931).The elephant-lore of the Hindus: The elephant-sport (Matangalila) of Nilakantha. Yale University Press, New Haven.

Ferrier, A.J. (1947).The care and management of elephants in Burma.Steel Bros. \& Co. London.

Jainudeen, M.R., McKay, G.M. \& Eisenberg, J.F. (1972). Observations on musth in the domesticated Asiatic elephant (Elephas maximus). Mammalia 36: 247-261.

Kahl, M.P. and Armstrong, B.D. (2002). Visual displays of wild African elephants during musth. Mammalia 66: 159-171.

Kurt, F. U., Mar, K. and Garai, E. (2008). History, biology, and preservation of Asian elephants in captivity. In Elephants and Ethics: Toward a morality of coexistence. Eds. Wemmer, C. \& Christen, C.A. pp.327-345. The Johns Hopkins University Press, Baltimore.

Lahiri-Choudhury, D.K. (1992). Musth in Indian elephant lore. In Elephants: Majestic creatures of the wild. (Ed) J. Shoshani. Rodale Press, Emmaus, PA Pp. 82-84.

Lehnhardt, J. and Galloway, M. (2008). Carrots and sticks, people and elephants. In Elephants and Ethics: Toward a morality of coexistence. (Eds) C. Wemmer \& C.A. Christen. The Johns Hopkins University Press, Baltimore Pp. 167182.

Lincoln, G.A. and Ratnasooriya, W.D. (1996). Testosterone secretion, musth behaviour and social dominance in captive male Asian elephants living near the equator. Journal of Reproductive Fertility 108: 107-113.

Markowitz, H. (1978). Engineering environments for behavioral opportunities in the Zoo. Behavior Analyst 1: 34-47.
Perry, J.S. (1954). The reproduction of African elephant, Loxodonta africana. Philosophical Transactions of the Royal Society, Section B237: 93-149.

Poole, J.H. (1987). Rutting behavior in African elephants: the phenomenon of musth.Behaviour, 102: 283-316.

Poole, J. (1996). Coming of age with elephants. Hyperion, New York.

Preecha, P., Lair, R.C. and Taweepoke, A. (2005). Elephant care manual for mahouts and camp managers. FAO, Bangkok.

Radhakrishnanan, S. (1950). The Dhammapada. Oxford University Press, Madras.

Rasmussen, L. E. L., $\quad$ Riddle, H. S., and Krishnamurthy, V. (2002). Chemical communication: Mellifluous matures to malodorous in musth. Nature 415: 975-976.

Rasmussen, L.E. (2003). Frontalin: a chemical message of musth in Asian elephants (Elephas maximus). Chem. Senses 28 (5): 433-446.

Sanderson, G.P. (1878). Thirteen Years among the Wild Beasts of India. W.H. Allan, London.

Santiapillai, C. and Widodo, S.R. (1992). Jungle four-wheel drive. Employing Asia's elephants for sustainable logging. Geographical., The Royal Geo. Soc. Magazine LXIV: 10-14.

Short, R.V. (1966). Oestrus behaviour, ovulation, and formation of the corpus luteum in the African elephant, Loxodonta africana. East African Wildlife Journal 4: 56-68.

Sukumar, R. (2003). The Living Elephants: Evolutionary Ecology, Behavior, and Conservation. Oxford University Press, Oxford.

Williams, H. (1989). Sacred Elephants. Jonathan Cape. London. 